\title{
Pacifier use and sudden infant death syndrome: results from the CESDI/SUDI case control study
}

Peter J Fleming, Peter S Blair, Katie Pollard, Martin Ward Platt, Charlotte Leach, Iain Smith, P J Berry, Jean Golding, and the CESDI SUDI Research Team

\begin{abstract}
Objectives-To investigate the relation between pacifier use and sudden infant death syndrome (SIDS).

Design-Three year population based, case control study with parental interviews for each death and four age matched controls.

Setting-Five regions in England (population > 17 million).

Subjects-325 infants who had died from SIDS and 1300 control infants.

Results-Significantly fewer SIDS infants $(40 \%)$ than controls $(51 \%)$ used a pacifier for the last/reference sleep (univariate odds ratio (OR), $0.62 ; 95 \%$ confidence interval (CI), 0.46 to 0.83 ) and the difference increased when controlled for other factors (multivariate OR, $0.41 ; 95 \% \mathrm{CI}$, 0.22 to 0.77 ). However, the proportion of infants who had ever used a pacifier for day (66\% SIDS $v 66 \%$ controls) or night sleeps $(61 \%$ SIDS $v 61 \%$ controls) was identical. The association of a risk for SIDS infants who routinely used a pacifier but did not do so for the last sleep became non-significant when controlled for socioeconomic status (bivariate OR, 1.39 (0.93 to 2.07)).
\end{abstract}

Conclusions-Further epidemiological

FSID Unit,

Department of Child

Health, Developmental

Physiology, Royal

Hospital for Children,

St Michael's Hill,

Bristol BS2 8BJ, UK

P Fleming

P S Blair

K Pollard

C Leach

P J Berry

J Golding

Newcastle Neonatal Service, Ward 35,

Royal Victoria

Infirmary, Newcastle upon Tyne NE1 4LP,

UK

$M$ Ward Platt

Nuffield Institute for Health, 71-75

Clarendon Road, Leeds LS2 9PL, UK

I Smith

Correspondence to:

Professor Fleming.

email: peter.fleming@

bris.ac.uk

Accepted 29 March 1999 drom Zealand, ${ }^{2}$ one from the Netherlands, ${ }^{3}$ and one form Norway, ${ }^{4}$ reported that the use of a pacifier might have a protective effect against sud- den infant death syndrome (SIDS). Because these findings raise the possibility that there may be a benefit as well as a risk from pacifier use, we investigated this in the study of sudden unexpected deaths in infancy undertaken within the Confidential Enquiry into Stillbirths and Deaths in Infancy (CESDI/SUDI) study, a large population based, case control study in the UK.

We report the relation between pacifier use and the risk of SIDS, in which we have examined both the effects of routine pacifier use and use specifically for the last sleep.

\section{Methods}

The study was conducted in five former NHS regions of England, with a population of 17.7 million. A case control study and confidential inquiry of all sudden unexpected postperinatal deaths (age 7 to 364 days) was conducted over a three year period from 1993 to 1996. Infants who died were ascertained through a communication network of professionals and lay organisations who reported all sudden unexpected deaths within 24 hours. Data were collected on a standard questionnaire by research interviewers, consistency of approach being maintained by regular training meetings. The interviewers visited each bereaved family twice. On the first occasion, usually within five days of the death, after obtaining informed consent they took a standardised semistructured history, including a narrative account of events leading up to and surrounding the infant's final sleep or death. On the second visit, a few days later and usually within two weeks of the death, they completed the full questionnaire.

Details of the methodology have been reported previously. ${ }^{5-7}$ The questionnaire included a total of over 600 fields, including demographic and social data; the medical history of the infant and other family members; use of cigarettes, alcohol, and drugs; the precise sleeping arrangements for the infant; and full details of the events preceding and the circumstances surrounding the death. Information was collected with regard to both the family's usual practices (including pacifier use) by day and by night, the last 24 hours of the infant's life, and the period when the baby died.

Four controls for each case were selected. The health visitor for the infant who died was asked to identify the two babies on her list next older and the two babies next younger, within two weeks of the age of the index baby. If a health visitor did not have four suitable babies on her own list she drew from the list of her 
nearest colleague. The interviewer visited each control family within a week of the death to collect the same data as for the index case. A period of sleep (the "reference sleep") was identified in the control infant's life in the 24 hours before the interview corresponding to the time of day during which the index baby had died, particular importance being given to the index parents' view of whether it had been a night or a daytime sleep. Data were collected for this period equivalent to those collected for the index baby.

A potential concern with all such studies is that parents of infants who have died may not give information as accurately as control families - their grief and distress at the death of their baby might mean that they do not give information on factors which they may regard as being undesirable (for example, pacifier use) or risky (for example, sleeping position). Although it is not possible to eliminate the possibility of such bias completely, the data collected from several sources in our study (the parents, the accident and emergency records, the pathologist, and the general practitioner) were remarkably consistent, even for information such as sleeping position, which was widely known to be a risk factor for SIDS at the time of our study. From this and previous studies using similar methodology, in which the parents of victims of SIDS were interviewed soon after the deaths, ${ }^{589}$ we believe that the data collected are accurate and relatively free from recall bias.

CLASSIFICATION OF THE “CAUSE" OF DEATH

A full paediatric postmortem examination was performed on all infants who died suddenly and unexpectedly, according to an agreed protocol. All deaths were reviewed at a multidisciplinary confidential inquiry meeting, at which the cause of death was classified according to the Avon clinicopathological scoring system. ${ }^{9}$ Our report deals only with those cases that were classified as SIDS, together with their matched controls. SIDS was defined as the sudden death of an infant, unexpected by history, for which no sufficient explanation was identified by the multidisciplinary panel after a

Table 1 Comparison of routine pacifier use by night or day

\begin{tabular}{|c|c|c|c|c|c|c|}
\hline \multirow[b]{2}{*}{ Night } & \multicolumn{2}{|l|}{ SIDS } & \multicolumn{2}{|l|}{ Controls } & \multirow[b]{2}{*}{ Univariate OR (95\% CI) } & \multirow[b]{2}{*}{ p Value } \\
\hline & $n=318$ & $\%$ & $n=1299$ & $\%$ & & \\
\hline \multicolumn{7}{|c|}{ Multicategorical } \\
\hline Never & 124 & 39.0 & 513 & 39.5 & 1.00 (reference group) & \\
\hline Sometimes & 93 & 29.2 & 316 & 24.3 & $1.14(0.82$ to 1.59$)$ & 0.45 \\
\hline Often & 24 & 7.5 & 130 & 10.0 & $0.78(0.46$ to 1.31$)$ & 0.35 \\
\hline Always & 77 & 24.2 & 340 & 26.2 & $1.00(0.70$ to 1.43$)$ & 0.99 \\
\hline \multicolumn{7}{|l|}{ Dichotomous } \\
\hline Never & 124 & 39.0 & 513 & 39.5 & 1.00 (reference group) & \\
\hline Ever & 194 & 61.0 & 786 & 60.5 & $1.03(0.78$ to 1.36$)$ & 0.86 \\
\hline Day & $n=318$ & $\%$ & $n=1298$ & $\%$ & & \\
\hline \multicolumn{7}{|c|}{ Multicategorical } \\
\hline Never & 107 & 33.6 & 448 & 34.5 & 1.00 (reference group) & \\
\hline Sometimes & 118 & 37.1 & 416 & 32.0 & $1.16(0.84$ to 1.60$)$ & 0.37 \\
\hline Often & 25 & 7.9 & 156 & 12.0 & $0.63(0.37$ to 1.05$)$ & 0.08 \\
\hline Always & 68 & 21.4 & 278 & 21.4 & $1.09(0.74$ to 1.61$)$ & 0.67 \\
\hline \multicolumn{7}{|l|}{ Dichotomous } \\
\hline Never & 107 & 33.6 & 448 & 34.5 & 1.00 (reference group) & \\
\hline Ever & 211 & 66.4 & 850 & 65.5 & $1.04(0.78$ to 1.38$)$ & 0.82 \\
\hline
\end{tabular}

CI, confidence interval; OR, odds ratio. full paediatric postmortem examination, review of the medical and social history, and assessment of the circumstances of the death. ${ }^{10}$

\section{STATISTICAL METHODS}

Testing for trends in the data was conducted using the $\chi^{2}$ test for proportions. If there was no obvious grouping, equal proportions using appropriate centile cut offs from the whole dataset were taken. Departure from linearity was also tested. Testing for differences within subgroups of particular variables was conducted using the Mantel-Haenszel test. Odds ratios (OR), 95\% confidence intervals (CI), and $\mathrm{p}$ values were calculated taking into account the matching using the statistical package SAS. ${ }^{11}$ The same package was used to conduct conditional logistic regression for the multivariate analysis, using the PHREG procedure to compare each index group with matched controls. Models were constructed using the stepwise method for selection of variables. Because the age distribution of the victims of SIDS and the control infants was slightly different, age was used as a mandatory covariate in all analyses.

Approval for our study was given by the local research ethics committees in each district in which the study was conducted. Informed consent was obtained from all parents of SIDS victims and control infants.

\section{Results}

ASCERTAINMENT

During the three year study period a total of 456 sudden unexpected deaths of infants were identified in the study regions. By a comparison with officially collected statistics on infant deaths (Office for National Statistics) we have subsequently identified a total of eight infant deaths in the study regions that met our entry criteria but were not included, mostly because the infants died outside the regions (ascertainment $98.3 \%$ ). Of these deaths, 363 were attributed by the multidisciplinary panels to SIDS. Our report deals with the results from the 325 victims of SIDS $(89.5 \%$ of the total) from whom full data were available for the index infant and the four matched controls. Although the age matching between cases and their matched controls was close, the controls were $\sim 10$ days older than the index infants. This was largely the result of the delays in making contact with the control families. As in the previously published two year study, ${ }^{8}$ our three year study showed no significant difference in the numbers of deaths on different days of the week.

\section{ROUTINE PACIFIER USE}

There was very little difference in routine pacifier use between victims of SIDS and the control infants (table 1) for either day or night sleeps, as either a multicategorical or dichotomous variable. The proportion of infants who usually used a pacifier at least sometimes by day or night was $68 \%$ for both index and control groups (OR, 1.03; 95\% CI, 0.77 to 1.38 ).

Table 2 stratifies the prevalence of routine pacifier use for possible confounders such as 
Table 2 Routine pacifier use stratified by age, socioeconomic status, breast feeding duration, and maternal smoking after pregnancy

\begin{tabular}{|c|c|c|c|c|}
\hline \multirow[b]{3}{*}{ Infant age * } & \multicolumn{4}{|c|}{$\begin{array}{l}\text { Proportion of infants who had ever used a pacifier (day } \\
\text { or night) }\end{array}$} \\
\hline & \multicolumn{2}{|l|}{ SIDS } & \multicolumn{2}{|l|}{ Controls } \\
\hline & $n$ & $\%$ & $n$ & $\%$ \\
\hline $0-8$ weeks & $53 / 88$ & 60.2 & $211 / 292$ & 72.3 \\
\hline $9-14$ weeks & $70 / 86$ & 81.3 & $253 / 356$ & 71.1 \\
\hline $15-22$ weeks & $54 / 75$ & 72.0 & $202 / 301$ & 67.1 \\
\hline 23 weeks or older & $40 / 69$ & 58 & $211 / 350$ & 60.3 \\
\hline$\chi^{2}$ test for trend & \multirow{2}{*}{\multicolumn{2}{|c|}{$\begin{array}{c}\mathrm{p}>0.5 \\
\mathrm{NA}\end{array}$}} & \multirow{2}{*}{\multicolumn{2}{|c|}{$\begin{array}{c}p<0.001 \\
p>0.1\end{array}$}} \\
\hline Test for departure from linearity & & & & \\
\hline Mantel-Haenszel & \multicolumn{4}{|c|}{$\mathrm{p}>0.9$} \\
\hline Socioeconomic status & $n$ & $\%$ & $n$ & $\%$ \\
\hline $\mathrm{V}$ or never employed & $57 / 70$ & 81.4 & $77 / 93$ & 82.8 \\
\hline III or IV & $134 / 198$ & 67.7 & $541 / 760$ & 71.2 \\
\hline I or II & $26 / 49$ & 53.1 & $256 / 443$ & 57.8 \\
\hline$\chi^{2}$ test for trend & \multicolumn{2}{|c|}{$\mathrm{p}<0.001$} & \multicolumn{2}{|c|}{$\mathrm{p}<0.001$} \\
\hline Test for departure from linearity & & & 0.75 & 0.50 \\
\hline Mantel-Haenszel & \multicolumn{4}{|c|}{$\mathrm{p}>0.90$} \\
\hline Duration of breast feeding ${ }^{\star \star}$ & $n$ & $\%$ & $n$ & $\%$ \\
\hline Never attempted & $130 / 181$ & 71.8 & $413 / 524$ & 78.8 \\
\hline $1-2$ weeks & $29 / 41$ & 70.7 & $128 / 169$ & 75.7 \\
\hline $3-6$ weeks & $28 / 41$ & 68.3 & $129 / 189$ & 68.3 \\
\hline $7-12$ weeks & $17 / 30$ & 56.7 & $121 / 204$ & 59.3 \\
\hline More than 12 weeks & $13 / 25$ & 52.0 & $86 / 212$ & 40.6 \\
\hline$\chi^{2}$ test for trend & \multirow{3}{*}{\multicolumn{2}{|c|}{$\begin{aligned} \mathrm{p} & <0.025 \\
0.50 & >\mathrm{p}>0.25\end{aligned}$}} & \multicolumn{2}{|c|}{$\mathrm{p}<0.001$} \\
\hline Test for departure from linearity & & & $\mathrm{p}<$ & $\star \star \star \star \Delta$ \\
\hline Mantel-Haenszel & & \multicolumn{3}{|c|}{$p>0.10$} \\
\hline Maternal smoking & $n$ & $\%$ & $n$ & $\%$ \\
\hline Does not smoke & $62 / 103$ & 60.2 & $597 / 931$ & 64.1 \\
\hline 1-9 cigarettes & $60 / 86$ & 69.8 & $119 / 158$ & 75.3 \\
\hline 10-19 cigarettes & $52 / 70$ & 74.3 & $106 / 142$ & 74.6 \\
\hline 20 or more cigarettes & $43 / 59$ & 72.9 & $54 / 66$ & 81.8 \\
\hline$\chi^{2}$ test for trend & \multicolumn{2}{|c|}{$0.10>p>0.05$} & \multicolumn{2}{|c|}{$p<0.001$} \\
\hline Test for departure from linearity & \multicolumn{2}{|c|}{ NA } & \multicolumn{2}{|c|}{$0.10>p>0.05$} \\
\hline Mantel-Haenszel & \multicolumn{4}{|c|}{$0.25>p>0.10$} \\
\hline
\end{tabular}

Maternal smoking refers to smoking after pregnancy.

${ }^{\star}$ Using approximate 25 th, 50 th, and 75 th centiles of whole data set as a cut off.

$\star \star$ Using approximate 25 th, 50 th, and 75 th centiles of all breast feeders as a cut off.

$\star \star \star$ When quadratic transformation was fitted $\mathrm{p}>0.25$.

infant age, socioeconomic status, duration of breast feeding, and the number of cigarettes the mother smoked. The proportion of pacifier users among the control infants decreased with increasing age, but this was not as apparent among the SIDS infants, mainly because of the comparatively small proportion of pacifier users below 2 months of age. For both groups, the proportion of pacifier users was lower for infants of families with higher socioeconomic status and for infants who breast fed for longer periods. The proportion of pacifier users increased with the number of cigarettes the mother smoked after pregnancy among the controls, but this did not reach significance among the victims of SIDS. Comparing the index and control infants within each stratum for potential confounding (using the MantelHaenszel test) the duration of breast feeding and the number of cigarettes smoked by the mother had the greatest effect, but neither reached significance.

PACIFIER USE FOR THE LAST/REFERENCE SLEEP Given the relative infrequency of pacifier use by some of the habitual pacifier users, it would be expected that the proportion of infants using a pacifier for the last or reference sleep would be smaller than the proportion of infants who had ever used a pacifier. Table 3 confirms this, but also shows that significantly fewer victims of SIDS (40\%) than control infants (51\%) used a pacifier. In the large multivariate model this association was strengthened when controlling for other variables. Specifically, if we controlled pacifier use for socioeconomic status, duration of breast feeding, or maternal smoking each of these factors increased the strength of the association with pacifier use, both individually and collectively (OR, 0.46; 95\% CI, 0.33 to 0.65).

Table 4 stratifies the proportion of infants who used a pacifier on the last/reference sleep for infant age, socioeconomic status, duration of breast feeding, and the number of cigarettes the mother smoked after pregnancy. As with routine pacifier use there was a negative correlation with increased duration of breast feeding and a positive correlation with increased maternal smoking and lower socioeconomic status. Although these trends were significant among both the victims of SIDS and the controls, testing within strata did not reveal any evidence of significant confounding. In contrast to the inverse relation between usual pacifier use and infant age (table 2), there was a positive relation between the proportion of users for the last/reference sleep and increasing age. Infants who had used a pacifier but did not do so for the last/reference sleep tended to be younger; over $60 \%$ of both the SIDS and control groups were $<3$ months old.

COMPARISON OF ROUTINE PACIFIER USE WITH USE ON LAST/REFERENCE SLEEP

Table 5 shows that in the univariate model there was a significant risk associated with usually using a pacifier but not doing so for the last/reference sleep. In a bivariate model, controlling for social class, pacifier use remained significantly associated with a reduced risk of SIDS and the risk associated with

Table 3 Pacifier use for the last/reference sleep

\begin{tabular}{|c|c|c|c|c|c|c|}
\hline & \multicolumn{2}{|l|}{ SIDS } & \multicolumn{2}{|l|}{ Controls } & \multirow[b]{2}{*}{ Univariate OR (95\% CI) } & \multirow{2}{*}{$\begin{array}{l}\text { Multivariate } O R^{\star} \\
(95 \% \mathrm{CI})\end{array}$} \\
\hline & $n=313$ & $\%$ & $n=1296$ & $\%$ & & \\
\hline Did not use a pacifier & 189 & 60.4 & 632 & 48.8 & 1.00 (reference group) & 1.00 (reference group) \\
\hline Used a pacifier & 124 & 39.6 & 664 & 51.2 & $0.62(0.46$ to 0.83$)$ & $0.41(0.22$ to 0.77$)$ \\
\hline
\end{tabular}

For multivariate analysis, the following factors were controlled for-maternal age, parity, gestational age, birthweight, multiple births, unemployment, maternal smoking during pregnancy, paternal smoking and drug use, daily postnatal exposure to tobacco smoke, previous episode of an apparent life threatening event, maternal anxiety over infant becoming too hot, breast feeding and factors relating to the last 24 hours including: put down in the prone or side position to sleep, where the infant slept, being found with head covered, use of pillow in the cot, recent maternal alcohol consumption, parental estimate of poor health, length of previous sleep, and change in routine affecting the infant.

$\mathrm{CI}$, confidence interval; OR, odds ratio. 
Table 4 Pacifier use for the last/reference sleep stratified by age, socioeconomic status, breast feeding duration, and maternal smoking after pregnancy

\begin{tabular}{|c|c|c|c|c|}
\hline \multirow[b]{3}{*}{ Infant age* } & \multicolumn{4}{|c|}{$\begin{array}{l}\text { Proportion of infants who used a pacifier for the } \\
\text { last/reference sleep }\end{array}$} \\
\hline & \multicolumn{2}{|c|}{ SIDS } & \multicolumn{2}{|c|}{ Controls } \\
\hline & $n$ & $\%$ & $n$ & $\%$ \\
\hline $0-8$ weeks & $24 / 85$ & 28.2 & $134 / 292$ & 45.9 \\
\hline 9-14 weeks & $35 / 85$ & 41.2 & $173 / 354$ & 48.9 \\
\hline $15-22$ weeks & $35 / 75$ & 46.7 & $162 / 301$ & 53.8 \\
\hline 23 weeks or older & $30 / 68$ & 44.1 & $195 / 349$ & 55.9 \\
\hline$\chi^{2}$ test for trend & \multirow{2}{*}{\multicolumn{2}{|c|}{$\begin{array}{c}\mathrm{p}<0.05 \\
0.25>\mathrm{p}>0.10\end{array}$}} & \multirow{2}{*}{\multicolumn{2}{|c|}{$\mathrm{p}<0.001$}} \\
\hline Test for departure from linearity & & & & \\
\hline Mantel-Haenszel & \multicolumn{4}{|c|}{$\mathrm{p}<0.001$} \\
\hline Socioeconomic status & $n$ & $\%$ & $n$ & $\%$ \\
\hline $\mathrm{V}$ or never employed & $34 / 67$ & 50.7 & $61 / 92$ & 66.3 \\
\hline III or IV & $74 / 197$ & 37.6 & $409 / 759$ & 53.9 \\
\hline I or II & $16 / 48$ & 33.3 & $193 / 442$ & 43.7 \\
\hline$\chi^{2}$ test for trend & \multicolumn{2}{|c|}{$\mathrm{p}<0.05$} & \multicolumn{2}{|c|}{$\mathfrak{p}<0.001$} \\
\hline Test for departure from linearity & \multicolumn{2}{|c|}{$0.50>p>0.25$} & \multicolumn{2}{|c|}{$0.90>\mathrm{p}>0.75$} \\
\hline Mantel-Haenszel & \multicolumn{4}{|c|}{$\mathrm{p}<0.001$} \\
\hline Duration of breast feeding $\star \star$ & $n$ & $\%$ & $n$ & $\%$ \\
\hline Never attempted & $81 / 179$ & 45.3 & $319 / 522$ & 61.1 \\
\hline $1-2$ weeks & $16 / 40$ & 40.0 & $100 / 169$ & 59.2 \\
\hline 3-6 weeks & $13 / 41$ & 31.7 & $92 / 189$ & 48.7 \\
\hline $7-12$ weeks & $8 / 29$ & 27.6 & $81 / 203$ & 39.9 \\
\hline More than 12 weeks & $6 / 24$ & 25.0 & $71 / 212$ & 33.5 \\
\hline$\chi^{2}$ test for trend & \multicolumn{2}{|c|}{$\mathrm{p}<0.01$} & \multicolumn{2}{|c|}{$\mathrm{p}<0.001$} \\
\hline Test for departure from linearity & \multirow{2}{*}{\multicolumn{2}{|c|}{$0.75>p>0.50$}} & \multicolumn{2}{|c|}{$0.25>p>0.10$} \\
\hline Mantel-Haenszel & & & \multicolumn{2}{|c|}{$\mathrm{p}<0.001$} \\
\hline Maternal smoking & $n$ & $\%$ & $n$ & $\%$ \\
\hline Does not smoke & $33 / 103$ & 32.0 & $450 / 929$ & 48.4 \\
\hline 1-9 cigarettes & $30 / 85$ & 35.3 & $76 / 157$ & 48.4 \\
\hline $10-19$ cigarettes & $38 / 70$ & 54.3 & $94 / 144$ & 65.3 \\
\hline 20 or more cigarettes & $23 / 55$ & 41.8 & $44 / 65$ & 67.7 \\
\hline$\chi^{2}$ test for trend & \multicolumn{2}{|c|}{$\mathrm{p}<0.025$} & \multicolumn{2}{|c|}{$\mathrm{p}<0.001$} \\
\hline Test for departure from linearity & \multirow{2}{*}{\multicolumn{2}{|c|}{$0.10>p>0.05$}} & \multicolumn{2}{|c|}{$0.25>p>0.10$} \\
\hline Mantel-Haenszel & & & & \\
\hline
\end{tabular}

Maternal smoking referes to maternal smoking after pregnancy.

${ }^{\star}$ Using approximate 25 th, 50 th, and 75 th centiles of whole data set as a cut off.

${ }^{\star \star}$ Using approximate 25 th, 50 th, and 75 th centiles of all breast feeders as a cut off.

usually using a pacifier but not doing so for the last/reference sleep became non-significant. In the multivariate model controlling for all significant factors, odds ratios and confidence intervals were similar to those for the bivariate model. In this multivariate model, all those factors (such as maternal smoking, socioeconomic status, bottle feeding, and infant illness) shown in our previous study ${ }^{1}$ to be significantly associated with pacifier use are included, and do not significantly affect the results of this analysis. Splitting the data into younger and older infants by dividing at the median age for the total SIDS group (those aged less than 101 days and those 101 days and older), pacifier use for the last/reference sleep remained significant in both the univariate and the bivariate models,

\section{Key messages}

- There was no difference between victims of SIDS and control infants in routine use of a pacifier ("dummy" or "soother") for day or night sleeps

- The use of a pacifier was associated with a lower prevalence and shorter duration of breast feeding, lower socioeconomic status, and mothers who smoked more heavily

- There was no association between pacifier use and sleeping position

- More control infants used a pacifier for the last/reference sleep, giving an apparent "protective" effect against SIDS; the significance of this association increased when controlled for other factors

- Further epidemiological evidence and physiological studies are needed before we can recommend pacifier use as protective against SIDS

indicating that pacifier use was not an age dependent variable in the models.

PACIFIER USE ON LAST/REFERENCE SLEEP AND SLEEPING POSITION

Similar proportions were put down prone among infants who used a pacifier $(13.9 \%$ SIDS group and $2.7 \%$ controls) or did not use one for the last/reference sleep ( $15.7 \%$ SIDS group and 3.3\% controls). Similar proportions were also found in the prone position among infants who used a pacifier (39.3\% SIDS group and $7.0 \%$ controls) or did not use one for the last $/$ reference sleep $(36.7 \%$ SIDS group and $5.3 \%$ controls).

\section{Discussion}

The similarity between the proportion of victims of SIDS and control infants reported as sometimes using a pacifier, and the similarity between this figure $(68 \%)$ and that found in our prospective population study (65\%) suggests that there was no systematic underreporting of pacifier use by parents of victims of SIDS. ${ }^{1}$

Our study confirms that there is an association between pacifier use and a reduced risk of SIDS. In addition, our study confirms the previously reported associations between pacifier use and infant feeding practices, parental

Table 5 Comparison of routine pacifier use and use for the last/reference sleep

\begin{tabular}{|c|c|c|c|c|c|c|c|c|}
\hline \multirow[b]{2}{*}{ Ever used a pacifier } & \multirow{2}{*}{$\begin{array}{l}\text { Pacifier for } \\
\text { last sleep }\end{array}$} & \multicolumn{2}{|l|}{ SIDS } & \multicolumn{2}{|l|}{ Controls } & \multirow{2}{*}{$\begin{array}{l}\text { Univariate } O R \\
(95 \% C I)\end{array}$} & \multirow[b]{2}{*}{ Bivariate OR $(95 \% \mathrm{CI})$} & \multirow[b]{2}{*}{ Multivariate OR $(95 \% \mathrm{CI})$} \\
\hline & & $n=313$ & $\%$ & $n=1296$ & $\%$ & & & \\
\hline No & No & 95 & 30.4 & 386 & 29.8 & 1.00 (reference group) & 1.00 (reference group) & 1.00 (reference group) \\
\hline Yes & No & 94 & 30.0 & 246 & 19.0 & $1.55(1.11$ to 2.18$)$ & $1.39(0.93$ to 2.07$)$ & $1.22(0.54$ to 2.74$)$ \\
\hline No & Yes & 5 & 1.6 & 36 & 2.8 & $0.56(0.17$ to 1.50$)$ & $0.37(0.10$ to 1.20$)$ & $0.65(0.06$ to 7.34$)$ \\
\hline Yes & Yes & 119 & 38.0 & 628 & 48.5 & $0.77(0.57$ to 1.05$)$ & $0.63(0.44$ to 0.91$)$ & $0.44(0.21$ to 0.94$)$ \\
\hline
\end{tabular}

In bivariate analysis occupational classification was controlled for.

In multivariate analysis the following factors were controlled for: maternal age, parity, gestational age, birth weight, multiple births, unemployment, maternal smoking during pregnancy, paternal smoking and drug use, daily postnatal exposure to tobacco smoke, previous episode of an apparent life threatening event, maternal anxiety over infant becoming too hot, breast feeding and factors relating to the last 24 hours including: put down in the prone or side position to sleep, where the infant slept, being found with head covered, use of pillow in the cot, recent maternal alcohol consumption, parental estimate of poor health, length of previous sleep, and change in routine affecting the infant.

CI, confidence interval; OR, odds ratio. 
smoking, and socioeconomic status, but controlling for these and other relevant factors (such as prone sleeping position) in a multivariate analysis strengthened the apparent protective effect associated with pacifier use. These observations, together with the unique size and the comprehensive nature of the data collected in the CESDI/SUDI study, suggest that the protective association is real.

The observations on pacifier use from New Zealand ${ }^{2}$ preceded the "back to sleep" campaign, yet found a magnitude of effect in a multivariate analysis (OR, 0.44; 95\% CI, 0.26 to 0.73 ) that was very similar to ours (OR, $0.44 ; 95 \% \mathrm{CI}, 0.21$ to 0.94$)$. In common with our study, the Dutch study ${ }^{3}$ took place after the change in recommendations on sleeping position and found an even stronger univariate association (OR, $0.06 ; 95 \% \mathrm{CI}, 0.01$ to 0.25 ). A recommendation derived from this study, to use a pacifier, has been widely publicised in Holland, despite serious reservations expressed by Righard. ${ }^{12}$ A study of routine pacifier use from Norway ${ }^{4}$ found a large difference in routine use between SIDS infants (10\%) and age matched controls (24\%). Thus, four studies from different countries have shown associations between pacifier use and a reduced risk of SIDS.

It is important to emphasise that the association does not necessarily imply that the use of a pacifier is "protective" against SIDS, although the finding is compatible with this hypothesis. Even with a large and careful case control study, we cannot be sure that parents of victims of SIDS who use a pacifier are not systematically different in some unmeasured way from the controls. The possibility remains that the use of a pacifier may be confounded with some other factor of parental behaviour that has not been identified by the questionnaire but which is the reason for apparent risk reduction. Although pacifier sucking has been shown to increase oxygen tensions in preterm infants ${ }^{13}$ there are no published physiological data that identify a mechanism by which pacifiers might protect against SIDS, and no evidence in the epidemiological studies for a "dose response" effect of pacifier use.

Unless or until other corroborative evidence becomes available, it follows that health professionals should be cautious in recommending routine pacifier use on the grounds of protection against SIDS. The evidence for recommending that all babies should be given pacifiers to reduce the incidence of SIDS is weaklevel III at best (US Agency for Health Care Policy and Research). Advice that is given routinely about the care of healthy babies must have at least as strong an evidence base as the treatment of those babies who are ill, because healthy babies are far more common, and the potential for unsuspected harm is relatively great, a lesson already bitterly learned for infant sleeping position.

It is widely believed that pacifiers have negative effects upon breast feeding, but few studies have considered this conflict in their conclusions, since pacifier use has been associated with both a decrease ${ }^{14} 15$ and no effect ${ }^{16}$ on the prevalence and duration of breast feeding. In our study there was a clear association between pacifier use and lower prevalence, as well as shorter duration of breast feeding, a finding compatible with a negative effect of pacifier use on breast feeding.

Pacifier use is associated with an increased incidence of respiratory and gastrointestinal illness. ${ }^{1}$ That this association may be causal is plausible, given the difficulties of maintaining pacifiers in a hygienic state. There is little hard evidence for other widely held beliefs about harmful effects of pacifiers on tooth growth, palatal anatomy, or speech development.

The association between pacifier use and a reduced incidence of SIDS needs to be explored further because of the implications for infant care practices if evidence for a causal link should become strong. This will require knowledge of the physiological effects of pacifier use, awake and during sleep, in health and disease; further epidemiological studies to explore risk factors not identified in the existing studies; and a full evaluation of potential harm as well as potential benefit. No recommendations on pacifier use can be made in the light of present knowledge.

This study was supported by research grants from the National Advisory Body for CESDI, the Foundation for the Study of Infant Deaths, and the International Children's Medical Research Association

1 North K, Golding J, Fleming PJ. Pacifier use and morbidity in the first six months of life. Pediatrics 1999;103:e34 (electronic pages: http://www.pediatrics.org/cgi/content/full/ 103/3/e34).

2 Mitchell EA, Taylor BJ, Ford RP, et al. Dummies and the sudden infant death syndrome. Arch Dis Child 1993;68: 501-4.

3 L'Hoir MP, Engelberts AC, van Well G Th J, et al. Case-control study of current validity of previously described risk factors for SIDS in the Netherlands. Arch Dis Child 1998;79:386-93.

4 Arnestad M, Anderson M, Rognum TO. Is the use of a dummy or carry-cot of importance for sudden infant death syndrome? Eur F Pediatr 1997;156:968-70.

5 Fleming PJ, Blair PS, Bacon C, et al. Environment of infants during sleep and risk of the sudden infant death syndrome: results from the 1993-1995 case-control study for confidential inquiry into stillbirths and deaths in infancy. BMF 1996;313:191-5.

6 Leach CEA, Blair PS, Fleming PJ, et al. Sudden unexpected deaths in infancy: similarities and differences in the epidemiology of SIDS and explained deaths. Pediatrics. [In press.]

7 Blair P, Fleming PJ, Bensley D, et al. Smoking and sudden infant death syndrome: results of $1993-5$ case-control study for confidential enquiry into stillbirths and deaths in infancy. BMF 1996;313:195-8.

8 Confidential Enquiry into Stillbirths and Deaths in Infancy. Third annual report. London: Department of Health, 1996.

Gilbert R, Rudd P Berry PJ, et al. Combined effect of infection and heavy wrapping on the risk of sudden unexpected infant death. Arch Dis Child 1992;67:171-7.

10 Lancet. Editorial. Unexplained deaths in infancy. Lancet 1999;353:161.

11 SAS Institute Inc. SAS user's guide. Cary, North Carolina: SAS Institute.

12 Righard L. Sudden infant death syndrome and pacifiers: a proposed connection could be a bias. Birth 1998;25:128-9.

13 Paludetto R, Robertson SS, Hack M, Shivpuri CR, Martin RJ. Transcutaneous oxygen tension during non-nutritive RJ. Transcutaneous oxygen tension during non-nutric
sucking in preterm infants. Pediatrics 1984;74:539-42.

14 Clements MS, Mitchell EA, Wright SP, Esmail A, Jones DR, Ford RPK. Influences on breastfeeding in southeast Ford RPK. Influences on breastfeed

15 Victoria CG, Behague DP, Barros FC, Olinto, MTA, Weiderpass E. Pacifier use and short breastfeeding duration: cause, consequence, or coincidence? Pediatrics 1997;99:445-53.

16 Schubiger G, Schwarz U, Tonz O. UNICEF/WHO baby-friendly hospital initiative: does the use of bottles and pacifiers in the neonatal nursery prevent successful breastfeeding? Eur f Pediatr 1997;156:874-7. 